If the SC had intended to reserve to itself the right to authorise force by means of a further resolution, it could obviously have done so. Indeed this approach was discussed informally by members of the Security Council but never became the subject of a draft resolution or vote; see Hansard, 25 November 2002 at page 53 (per the Foreign Secretary).

The SC could also have qualified its reference to resolutions 678 and 687, and thus made it clear that member states could not use force to deal with the threat posed to peace and security by Iraq. It did not do so. The fact that there is now some disagreement as to what was meant by SCR 1441 cannot prevent the words of that resolution (or indeed the earlier resolutions) from carrying their plain and ordinary meaning.

\section{CONCLUSION}

The use of necessary and proportionate force, in accordance with international humanitarian law by coalition forces, to neutralise the threat posed by Saddam Hussein's failure to comply with UN imposed disarmament obligations can be rooted in:

- SCR 678 (authority to use force);

- SCR 687 (the requirement for the Iraqi regime to, inter alia, disarm so as to remove the threat to international peace and security it posed);
- SCR 1441 (confirmation of SCR's 678, 687, and of the fact that Iraq's continued non-compliance with disarmament obligations triggered serious consequences).

Post intervention, emerging issues are likely to include the following:

- Possible attempts to challenge the intervention at the International Court of Justice (compare with the attempt to challenge the NATO action in Kosovo in March 1999);

- Possible attempts to persuade the DPP to carry out a "war crimes" investigation in the event that UK forces bomb civilian targets and/or an argument can be made to this effect;

- War crimes trials/asset freezing action in respect of Saddam and/or his accomplices;

- Security Council interaction on humanitarian issues and post conflict issues in Iraq - potential for other states to use this as a platform to condemn the intervention and/or using this to effect "retrospective legitimacy". 숭

\title{
State protection of the child - mirage or reality?
}

by Dr Ya'ir Ronen

My central point in this article is that state protection of the child as projected by the legal rhetoric of child protection law is a mirage in that it gives the misleading impression of comprehensive protection to the child from all harm while typically failing to offer such protection.

$I^{2}$ base my view on child protection on an analysis of domestic legislation and case law in several domestic jurisdictions. It is important to clarify at the outset that I can only attempt to convince the reader of a general pattern of distortion and that different legal systems differ in the degree of compatibility between the reality of child
My thesis is based around the following six complementary claims:

1. Child protection law is typically perceived through its aims and mandates as offering the child comprehensive protection from all harm.

2. These aims and mandates disguise a preoccupation 
with protection from individuals directly responsible for bringing up the child.

3. Consideration of the child's best interests as the paramount consideration under laws aimed at remedying harm already done to the child is not equivalent to comprehensive responsibility for the child, but nevertheless diverts attention from a lacking infrastructure of social rights.

4. The ethos of liberal individualism as implied in child protection case law and literature often ignores some of the child's fundamental needs.

5. The language of needs when not coupled by recognition of legal participation rights within child protection law is liable to distort the child's story and the meaning he/she gives to her suffering and well being.

6. In certain situations legal principles when not translated to unequivocal rules mandating specific state action are liable to expose the child to continued harm.

\section{A LANGUAGE OF COMPREHENSIVE PROTECTION FROM ALL HARM}

A child in need of state protection is often defined as any child who may suffer emotional or physical harm. The aim of child protection law is often formulated as the prevention of all such harm to the child, whether by action or by inaction. Most legal systems do not adopt a narrow definition of child abuse enumerating a conclusive list of factual situations of abuse. An open-ended definition of abuse allows responsiveness to different types of abuse. Different laws enumerate different instances of abuse and neglect, only a few of which explicitly mention the behavior of the child's parents or that of those responsible for him/her.

\section{BRINGING UP CHILDREN AND STATE PROTECTION OF CHILDREN}

These laws allow those interpreting them to believe that the primary risk to the child derives from those directly responsible for him/her and that from them the law should primarily aim to protect him. Law can protect children through proof of need. By seeing parents as solely responsible for responding to the child's needs, law is liable to become preoccupied with evidential issues of parental wrongdoing in order to justify intervention. I am not convinced that this preoccupation as inevitable or deriving from the fundamental nature of the law. I suggest it be seen as a challenge to recognize more fully the child's needs.

\section{THE MEANING OF PARAMOUNCY OF CHILDREN'S INTERESTS IN REMEDYING HARM TO THE CHILD}

Once harm to the child has been identified, his/her interests are often paramount and he/she may receive a remedy under child law despite infringement on the interests of others such as biological kin, foster parents or adoptive parents.

There has been an ongoing struggle between children's rights proponents and proponents of family autonomy and parental rights, and the present state of child protection law signifies clear progress for those championing the child's interests. State protection from harm is widening its scope and mandating greater intervention into family life, thus infringing on what were perceived in the past as parental rights. This trend is mirrored in legislation and case law relating to domestic violence, adoption and guardianship. These fields of law become more and more child-centred in the remedies offered once harm to the child is identified. This state of affairs is liable to be equated with the paramouncy of children's interests under law. Commitment to children's interests in specific situations of proven harm and the tone of compassion towards their suffering in case law, public inquiries and Parliamentary debates may naturally lead one to the conclusion that this commitment mirrors comprehensive state responsibility for the child.

We are thus tempted to forget what is probably the main insight deriving from the legacy of Goldstein, Solnit and Freud in their trilogy "In the best interests of the Child", an insight incorporated into case law in different jurisdictions when dealing with the determination of the disputed guardianship of children. State action to protect the child is always only the least detrimental alternative and therefore cannot be equated with paramouncy of children's interests under law. Therefore, according children's interests paramouncy in situations where remedies for harm which already occurred are sought and offered by the state cannot be seen as mirroring comprehensive state protection

\section{THE ETHOS OF LIBERAL INDIVIDUALISM AND CHILDREN'S FUNDAMENTAL NEEDS}

An ethos of liberal individualism does not foster state responsibility for hunger, homelessness, a violent educational environment or inadequate healthcare or the non-existence of counselling services. It is concerned primarily with liberties, but hungry or bullied children, those who have been separated from their parents because they became homeless, or have no recourse to counselling may invest all their personal resources into physical and emotional survival. They have little interest in civil liberties such as freedom of expression or freedom of conscience. They have little chance of becoming autonomous adults who will implement liberties, as liberal theory would imagine adults as able of doing. They often perceive their civil liberties as useless to them and to a degree their perception makes sense from a psychological resiliency perspective.

This ethos forces some writers to opt to an economic rationale to justify Social rights as part of child protection 
law. Furthermore, children often have a complex set of identifications and despite abuse or neglect within their families and communities, ties with these often remain important to them. An atomistic or individualistic ethos does not foster authentic self-actualization cognizant of the vitality of such ties to the formation of identity. We have to remember that protection of the child's identity and autonomy interest is different from protecting those of adults. Liberal individualistic rights discourse is liable to aid reconstruction of a social problem - the problem of harm to children - as a bundle of private disputes between individuals. According to this reconstruction, the sole role of the state is advocacy of the child in relation to those who are intimately responsible for his well being.

The well accepted imagery of the state as one corner of a triangle with parents and children as the other corners is one expression of this reconstruction. It is an imagery of rivalry and competition. Though the state and parents may at times need to compete and be rivals in a struggle to define what is best for the child and uphold children's interests despite parental opposition, this individualist imagery is distorting. For children to develop their potential the state should essentially be one of many resources the child has.

\section{THE LANGUAGE OF NEEDS AND DISTORTION OF THE CHILD'S STORY}

Despite my criticism of liberal individualism - an ethos which often underlies claims for children's rights, especially participation rights - recognition of children's participation rights seems indispensable if state responsibility for child protection is to become a reality.

Seeing a child care professional as a sole expert in the definition of the child's rights is dis-empowering to the child. The child may find it difficult to express anger and frustration towards the professional when he feels injustice has been done to him/her. A child who has no right to participate in defining what are abuse and neglect and what is protection from them under law cannot effectively challenge professional thinking of children in need of protection solely as children with problems. A child's creative ability to overcome adversity is thus liable to be ignored.

I suggest that recognition of participation rights enables new stories to be heard and expose the limitations of our present understanding as to the injustices and suffering endured by children.

\section{PRINCIPLES, RULES AND CONTINUATION OF PREVENTABLE HARM}

Certainly adequate protection of children's rights demands an often-complicated act of balancing between competing interests of children. However, this seems to have been used as an excuse not to formulate and enforce unequivocal legal rules in situations where there is clear harm to the child if a certain course of state action is not taken. My claims is that we may over-complicate child protection law, thereby denying the child social rights and maintaining a mirage of state responsibility for the child. However the infrastructure for change is present through social science literature and the conceptual framework of international child law.

To cite one example of a starting point, the UN guidelines for the prevention of juvenile delinquency offer a set of guidelines which mirror recognition of the harm caused by entering formal systems such as the child protection system or the juvenile justice system, and emphasize preventive policies. Their title may be wrongly perceived as inaccurate as they adopt a proactive preventive approach to juvenile delinquency which does not target mainly those who have been identified as juvenile offenders, but much larger populations. Child protection law does not, typically, adopt the widely framed aims of the guidelines, and nor does it, typically, implement the policy outlines in the guidelines.

The guidelines, which lack binding legal force in domestic laws, have yet to be implemented through social rights geared to respond to the child's needs in the specific child protection context.

\section{SUMMARY}

My conclusions derive from my claims: I believe the human rights community needs to engage in a serious debate as to the allocation of social rights to the child in the child protection context, and for that purpose must reexamine the problematics of liberal individualism as its underlying ethos. Adoption of preventive policies which aim to protect both the child's autonomy and identity can be responsive to different trends in child law, such as the recognition of open adoption or prevention of juvenile delinquency and school exclusion.

Legal principles translated to unequivocal rules mandating specific state action may offer the child more realistic protection, and divert some attention from parents or professionals (who may indeed be blameworthy, but only to a degree). The legal reform envisioned cannot but challenge the perception that society is committed to child protection by exposing the ambivalence of comprehensive protection. I claim this is a worthy challenge. (c)

\section{Dr Ya'ir Ronen}

Bar Ilan Universit; Queen Mary College, University of London

This article is taken from a lecture given at the Institute of Advanced Legal Studies. 